
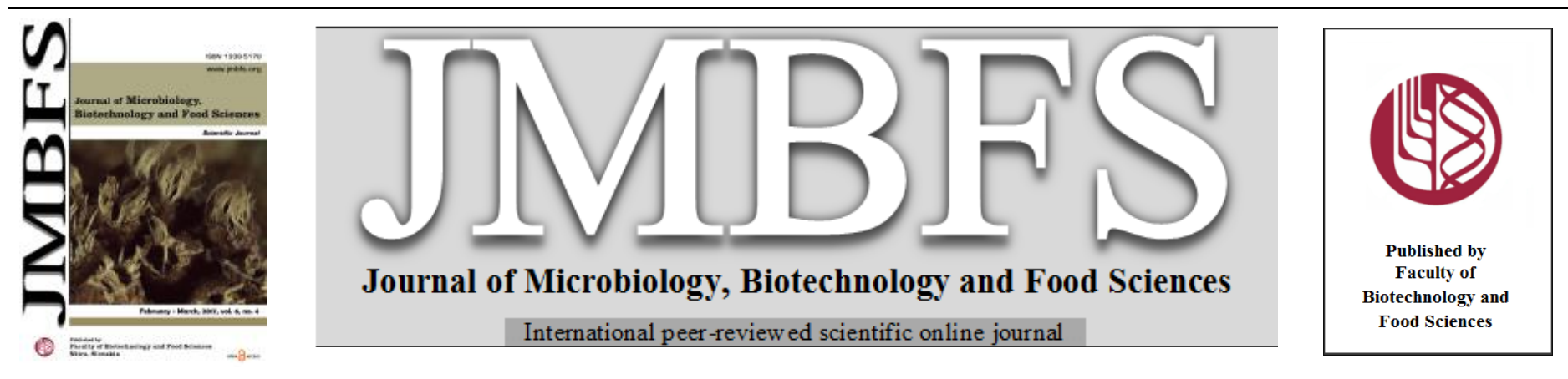

\title{
EFFECT OF DIFFERENT TYPES OF COAGULATING AGENT ON PHYSICO-CHEMICAL AND ORGANOLEPTIC PROPERTIES OF NON DAIRY RASGULLA (CHEESE BALL)
}

\author{
Samadrita Sengupta ${ }^{1}$, Anwesha Samanta ${ }^{2}$, Jayati Bhowal $*^{3}$ \\ Address(es): Jayati Bhowal, \\ ${ }^{1}$ IIEST, Shibpur, PhD Research Fellow, SOCSAT, Botanic Garden, 711 103, Howrah, West Bengal, (+91) 9903780850. \\ ${ }^{2}$ IIEST, Shibpur, MSc, SOCSAT, Botanic Garden, 711 103, Howrah, West Bengal, (+91) 7278625034. \\ ${ }^{3}$ IIEST, Shibpur, Assistant Professor, SOCSAT, Botanic Garden, 711 103, Howrah, West Bengal, (+91) 9831672455.
}

*Corresponding author: jayatibhowal@gmail.com

doi: $10.15414 / j m b f s .2017 .6 .4 .1107-1111$

ARTICLE INFO

Received 15.8. 2016

Revised 18. 10. 2016

Accepted 5. 1. 2017

Published 1. 2. 2017

Regular article

open $O$ access

\begin{abstract}
Non-dairy rasgulla NDR (cheese ball) were manufactured from soybean milk using different types ofcoagulants such as citric acid, lactic acid, tartaric acid and calcium lactate ( $2 \%$ each). Dairy rasgulla procured from local market was used as control (DR). This study investigated the effects of these coagulants on the physico-chemical, color, in vitro multienzyme protein digestibility and the sensory properties of DR and NDRs.Citric acid coagulated NDR (CNDR) recorded high fat value $(4.95 \pm 0.18 ; \mathrm{p}<0.05)$ among all the NDRs. Protein value of DR $(8.24 \pm 0.05 ; \mathrm{p}<0.01)$ was higher than lactic acid coagulated rasgulla (LNDR) $(7.89 \pm 0.22 ; \mathrm{p}<0.01)$, but was lower than the values obtained for other three types of NDRs. The moisture content of LNDR $(51.20 \pm 0.56 ; \mathrm{p}<0.01)$ was significantly higher than that of other NDRs. Among NDRs, the LNDR recorded highest carbohydrate content $(34.37 \pm 0.49 ; \mathrm{p}<0.01)$. The energy value of LNDR $(208.55 \pm 6.88 ; \mathrm{p}<0.01)$ was significantly lower than that of all other NDRs. Penetration values of all the five types of rasgulla sample were gradually decreased during the storage period.A similar trend of $\mathrm{L}^{*}$ values (lightness) was observed in case of CNDR and DR. The mean scores of DR and NDRs for color, aroma, texture and overall acceptability were gradually decreased during storage. It was observed that CNDR, tartaric acid coagulated rasgulla (TNDR) and calcium lactate coagulatedrasgulla (CLNDR) had higher overall acceptability than DR. LNDR, CNDR and CLNDR had lower protein digestibility values than DR. On the basis of analysis of different physicochemical and sensory parameters, tartaric acid proved to be optimum in the preparation of NDR.
\end{abstract}

Keywords: Rasgulla, Soymilk, Channa, Penetration, Digestibility

\section{INTRODUCTION}

Rasgulla, the sweet syrupy cheese ball is one of the most popular and charming sweets of India (Bandyopadhyay et al., 2008). Rasgulla is made from heat and acid coagulant milk protein mass traditionally known as chhana which is kneaded into small balls that are boiled into 40-60\% sugar syrup. Rasgulla is generally made from cow milk (Rao et al., 1989) and very few reports are there regarding the manufacture of rasgulla from buffalo milk (Kanwal et al., 1980). This dairy product is easily digested and has high food value due to its fairly high protein content, calcium, phosphorus, vitamin A and D content (Tarafdar et al., 2002) Rasgulla are extensively consumed due to its good nutritional and health benefit to human (Chavan et al., 2011; Sahu and Das, 2009). Production of non-dairy food products from non-conventional edible seed flour such as soybean has emerged as popular alternative to traditional dairy products due to ongoing trends of vegetarianism, milk cholesterol, saturated milk fat and lactose intolerance. Soybean which is the most widely grown and utilized legumes in the world has good amino acid profile, contain higher levels of essential fatty acids, soluble fiber, vitamins, minerals, phytochemicals which include isoflavones, phytic acid and saponins which have strong antioxidant properties and have capability of lowering the cholesterol level (Barrett,2006). Soy based food products have attained significant consideration for their potential role in improving health hazards such as risk factors for coronary heart disease. Soy foods such as soymilk, tofu, natto, miso, tempeh, textured vegetable protein like soy burgers, soy nuts and whole soybeans may offer various health benefits (Jooyandeh, 2011; Sengupta et al., 2016). As a suitable alternative for probiotic dairy products, soy beverages and yogurts are another food category for which the healthy bacteria has played an important role in preventing health related disease outcome.Traditional soy foods, both fermented and non-fermentedproducts, are part of the daily diet in many areas of the world. Products such as soy sauce tofu, tempeh and others are richer in aglycone, and isoflavones than unfermented soy products and are becoming more popular in our country (Wang and Murphy,
1994). Because of this development, rasgulla from soy milk is very challenging and people have started to take an interest in soy product consumption.

Food value of rasgulla largely depends upon the quality of chhana. The type of coagulant used for coagulation of vegetable milk has prominent role in maintaining quality of chhana as it regulates the moisture content in chhana. Generally organic acids like citric, lactic acid, tartaric acid, calcium lactate, lemon juice and sour whey are used as coagulant. Effects of different coagulating agents in the production of dairy rasgulla (DR) have been reported (Soni et al., 1980; Ahmed et al., 1981; Bandyopadhyay et al., 2005) but, there is no information regarding the effects of different coagulants in the preparation of chhana to manufacture rasgulla from soy milk.

The objective of this study was to prepare soy based rasgulla coagulated with different coagulating agents. Effects of different coagulants on the physicochemical, sensory and general acceptability of non-dairyrasgulla(NDR) were studied and compared with those of dairy rasgulla.

\section{MATERIAL AND METHODS}

Chemicals and reagents

Soybean seeds were purchased from the local market (New Alipore Market, Kolkata West Bengal, India). Polyethylene cups and aluminum foil were procured from the local market. Citric acid, lactic acid, tartaric acid and calcium lactate were obtained from MERCK (Emerck India Ltd. Mumbai, India). All other chemicals were of analytical grade. Dairy rasgulla was brought from sweet shop (Hindusthan sweets, Newalipore, Kolkata, W.B., India). Double refined cane sugar and rose water were obtained from local shop of New Alipore, Kolkata. 


\section{Preparation of soy milk}

The preparation of soy milk from whole soy seeds was described by adopting the procedure of Sengupta et al., (2013).

\section{Preparation of coagulant solution}

Citric, lactic acid, tartaric acid and calcium lactate were used as coagulant and each of them $(2 \%)$ was dissolved in distilled water separately to prepare coagulant solution (Aneja et al., 2002).

\section{Preparation of Chhana and Rasgulla (Cheese ball) from soy milk}

Chhana and rasgulla were prepared from soy milk using the method suggested by Aneja et al., (2002) but with a slight modification. Schematic diagram for the preparation of chhana and rasgulla was given in Fig $\mathbf{1 .}$

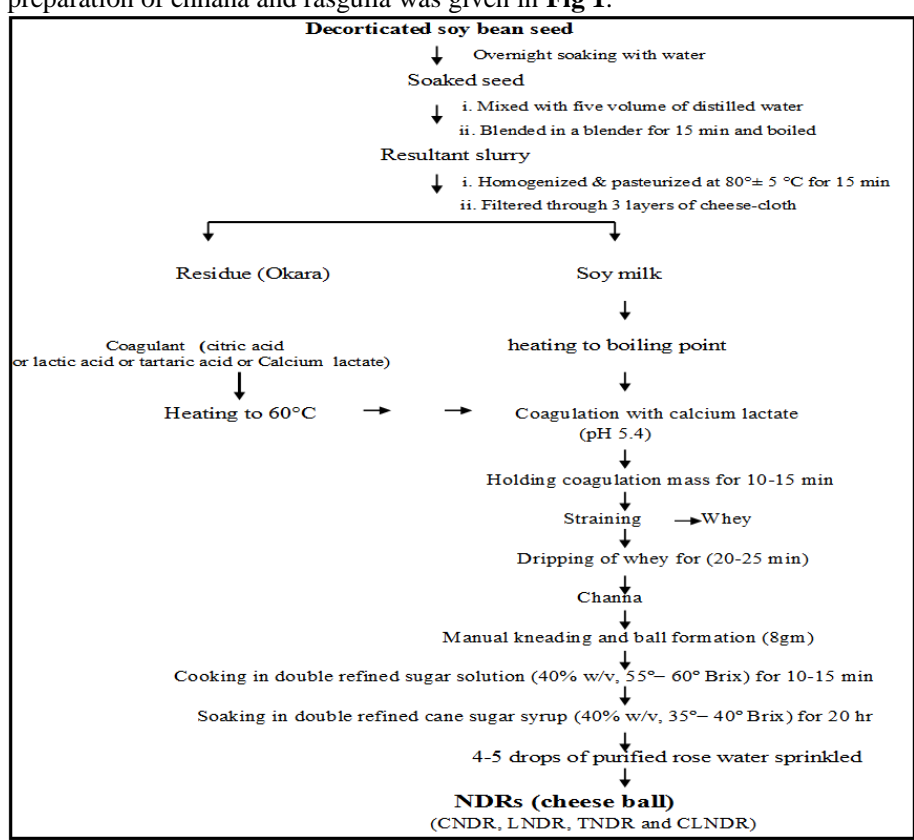

Fig 1 Flow diagram for manufacturing NDR from soymilk

NDRs: non-dairy rasgullas; CNDR: citric acid coagulated non-dairy rasgulla; LNDR: lactic acid coagulated non-dairy rasgulla; TNDR: tartaric acid coagulated non-dairy rasgulla; CLNDR: calcium lactate coagulated non-dairy rasgulla.

After completion of precipitation of soya milk ( $\mathrm{pH}$ 5.4) with coagulating agent, chaana was collected in a cheese cloth and the whey was drained off by squeezing the lump (milk solid) as much as possible (20-25 min). The lumps of chhana were softened uniformly by messing. Chhana was kneaded thoroughly until visible separation of fat was occurred on the palms to form dough. This dough was converted to chhana balls by rolling between hand palms for $1 \mathrm{~min}$ without forming any crack on the balls surface (Yadav et al., 2012) otherwise these balls usually lost their integrity during cooking. For cooking and soaking of rasgulla cooking syrup $\left(40 \% \mathrm{w} / \mathrm{v}, 55^{\circ}-60^{\circ}\right.$ Brix) and soaking syrup $\left(35^{\circ}-40\right.$ ${ }^{\circ}$ Brix) were prepared separately. The chhana balls $(8 \mathrm{gm})$ made by differen coagulants were cooked in the boiled cooking syrup solution for 10-15 minutes The cooked balls were then collected from the deep pan and placed in the freshly prepared soaking syrup solution for $20 \mathrm{hr}$ in which 4-5 drops of purified rose water was sprinkled. Dairy rasgulla purchased from local shop was used as control. Four different types of NDRs were manufactured and designated as CNDR: citric acid coagulated non-dairy rasgulla; LNDR: lactic acid coagulated non-dairy rasgulla; TNDR: tartaric acid coagulated non-dairy rasgulla; CLNDR: calcium lactate coagulated non-dairy rasgulla. The control dairy rasgulla (DR) and non-dairy rasgullas (NDRs) were stored in closed container at $4{ }^{\circ} \mathrm{C}$ for 30 days.

\section{Proximate composition of DR and NDRs}

The proximate composition (protein, fat, moisture, total solids and ash content) of DR and NDRs from different coagulants were carried out in triplicate using the standard methods of AOAC, (2005). Fat was determined according to Bligh and Dyer (1959) method by some process modification. Carbohydrate content was calculated by difference [100- (moisture + crude protein + lipid + ash)]. Energy values were obtained using the Atwater formula (Merrill and Watt, 1973).

\section{Penetration property of DR and NDRs}

The penetration property of DR and NDRs were determined by a Penetromete (Stanhope-Seta Surrey, England) using the cone-form penetration body with an apical angle of $45^{\circ}$ and a weight of $72.5 \mathrm{~g}$ (Sanli et al., 2013). The depth of penetration was measured at $5 \mathrm{~s}$ at a product temperature of $25^{\circ} \mathrm{C}$.

\section{Colour property of DR and NDRs}

Color intensities in DR and NDRs were measured by use of the colorimeter (Konica Minolta CR 10) which gave the Hunter parameter $\left(\mathrm{L}^{*}, \mathrm{a}^{*}, \mathrm{~b}^{*}\right)$ and also $\mathrm{c}^{*}$ and $\mathrm{h}^{*}$ values directly (Morales and Boeckel, 1999). Rasgulla samples were homogenized in a homogenizer and $5 \mathrm{~g}$ of homogenized samples were placed in Petridishes with a cover. Colour was measured within 5 min of the sample preparation. $\mathrm{L}^{*}$ indicated lightness which describes the light reflecting or transmitting capacity of an object. Color analysis was also performed by determination of $\mathrm{a}^{*}$ ( - green to + red component), $\mathrm{b}^{*}$ (-blue to yellow), $\mathrm{c}$ (chroma) and $\mathrm{h}^{*}$ (hueangle) values in triplicates.

\section{Sensory evaluation of DR and NDRs}

Freshly prepared DR and NDRs were kept at $37^{\circ} \mathrm{C}$ for $24 \mathrm{~h}$ for sensory evaluation. 20 members were chosen from School of Community Science and Technology, IIEST, Shibpur, Howrah, West Bengal. They developed a consensus evaluation for flavor attributes for DR and NDRs and the evaluation was carried out at Nine Point Hedonic Scale. The quality properties that were evaluated were color, taste, flavor and overall acceptance. The quality information contained on the sensory performance was indicated as $9=$ like extremely, $8=$ like very much, $7=$ like moderately, $6=$ like slightly, $5=$ neither like or dislike, $4=$ dislike slightly, $3=$ dislike, $2=$ dislike very much, 1=dislike extremely (Sengupta et al., 2013).

\section{In vitro multienzyme protein digestibility of DR and NDRs}

The in vitro protein digestibility of DR and NDRs was carried out using the method of Hsu et al., (1977). A suspension of the rasgulla from each coagulant was prepared by dissolving $1.75 \mathrm{gm}$ in $50 \mathrm{ml}$ distilled water. The $\mathrm{pH}$ of the suspension was adjusted to 8.0 with $0.1 \mathrm{M} \mathrm{NaOH}$, while stirring in a water bath at $37^{\circ} \mathrm{C}$. A multienzyme solution consisting of $1.6 \mathrm{mg} \mathrm{mL}^{-1}$ trypsin, $3.1 \mathrm{mg} \mathrm{mL}^{-1}$ chymotrypsin and $1.3 \mathrm{mg} \mathrm{mL}^{-1}$ peptidase was kept in an ice bath and adjusted to pH 8 with $0.1 \mathrm{M} \mathrm{HCl}$. $0.05 \mathrm{~mL}$ of the multienzyme solution was added to each rasgulla sample suspension and was constantly stirred at $37^{\circ} \mathrm{C}$. The $\mathrm{pH}$ of the suspension was recorded $15 \mathrm{~min}$ after the addition of the multienzyme solution and the in vitro digestibility was calculated using the regression equation of Hsu et al., (1977).

\section{$\mathrm{Y}=210.46-18.10 \mathrm{X}$}

Where, $\mathrm{Y}=$ in vitro digestibility $(\%)$ and $\mathrm{X}=\mathrm{pH}$ of the sample suspension after 15 min digestion with the multienzyme solution.

\section{Statistical analysis}

Statistical analysis of data collected from different parameters was performed by using analysis of variance (ANOVA) and the means were compared across groups by Tukey test. All analyses were carried out in triplicates with the OriginPro 8 and the significant differences were determined at $\mathrm{p} \leq 0.05$.

\section{RESULTS AND DISCUSSION}

\section{Proximate composition of DR and NDRs on 0 day at $4^{\circ} \mathrm{C}$ in a refrigerator}

Table 1 represented the proximate composition of DR and NDRs and it was found that there were significant differences in the proximate composition of NDRs $(\mathrm{p} \leq 0.05)$ in comparison with DR. CNDR recorded high fat value $(4.95 \pm 0.18 ; \mathrm{p}<0.05)$ followed by LNDR $(4.39 \pm 0.17 ; \mathrm{p}<0.05)$, TNDR $(4.23 \pm 0.16$ $\mathrm{p}<0.05)$ and CLNDR $(3.56 \pm 0.15 ; \mathrm{p}<0.01)$. Control DR had higher fat value $(7.86 \pm 0.29 ; \mathrm{p}<0.05)$ than those of all the NDRs. These values of fat are higher than the values (1-1.2\%) obtained by Garg et al., (2014). The same value about fat content of soy rasgulla was observed by Nande $\boldsymbol{e t}$ al., (2008). They also showed that fat content in freshly prepared soy based rasgulla was low as compared to dairy rasgulla. Bhattacharya and Raj (1980) also reported lesser fat content in non-dairy rasgulla which was due to lesser fat content in non-dairy channa.

TNDR recorded high value of protein $(16.28 \pm 0.38 ; \mathrm{p}<0.01)$ followed by CLNDR $(15.24 \pm 0.36 ; \mathrm{p}<0.05)$, CNDR $(13.67 \pm 0.35 ; \mathrm{p}>0.05)$ and LNDR $(7.89 \pm 0.22$ $\mathrm{p}<0.01)$. Protein value of DR $(8.24 \pm 0.05 ; \mathrm{p}<0.01)$ was higher than LNDR $(7.89 \pm 0.22 ; \mathrm{p}<0.01)$, but was lower than the values obtained for other three types of NDRs.

The moisture content of LNDR $(51.20 \pm 0.56 ; \mathrm{p}<0.01)$ was significantly higher than that of other NDRs. The variation in the moisture content of NDR prepared with different coagulants was probably due to the differences in gel network within the non-dairy rasgulla particles that was influenced by different coagulating agents towards the water holding capacity of soy protein gels. It may 
also be due to the unique coagulating properties of different coagulating agents (Yakubu, et al., 2013).

Carbohydrate content of DR $(36.57 \pm 0.51 ; \mathrm{p}<0.01)$ was highest among all the five types of rasgulla samples. Among NDRs, the LNDR recorded highest carbohydrate content $(34.37 \pm 0.49 ; \mathrm{p}<0.01)$ followed by CLNDR $(32.27 \pm 0.43$; $\mathrm{p}<0.01), \mathrm{CNDR}(30.72 \pm 0.45 ; \mathrm{p}>0.05)$ and TNDR $(29.65 \pm 0.43 ; \mathrm{p}>0.05)$. Table 1 also showed the result of energy content of NDRs prepared using different coagulants. The energy value of LNDR $(208.55 \pm 6.88$; $\mathrm{p}<0.01)$ was significantly lower than that of CNDR $(222.11 \pm 9.00 ; \mathrm{p}<0.05)$, TNDR $(221.79 \pm 7.50 ; \mathrm{p}<0.05)$ and CLNDR $(222.08 \pm 7.40 ; \mathrm{p}<0.05)$. The energy value of DR was relatively higher than all NDRs. It was reported that rasgulla containing low-fat and high protein was helpful in lowering body weight (Kolanowski, 1977). Dairy rasgulla when stored at refrigerated condition had a shelf life of more than 40 days and not more than 6 days at room temperature.

Table 1 Proximate composition of DR and NDRs using different coagulating agentson 0 day at $4{ }^{\circ} \mathrm{C}$ in a refrigerator

\begin{tabular}{|c|c|c|c|c|c|}
\hline \multirow[t]{2}{*}{ Proximate Composition (\%w/w) } & \multirow[t]{2}{*}{ DR } & \multicolumn{4}{|l|}{ NDRs } \\
\hline & & CNDR & LNDR & TNDR & CLNDR \\
\hline Moisture & $46.29 \pm 0.55$ & $47.24 \pm 0.53$ & $51.20 \pm 0.56^{\mathrm{b}}$ & $46.25 \pm 0.53$ & $45.29 \pm 0.52^{\mathrm{a}}$ \\
\hline Total solids & $53.71 \pm 0.60$ & $52.76 \pm 0.60$ & $48.80 \pm 0.55^{\mathrm{b}}$ & $53.75 \pm 0.61$ & $54.71 \pm 0.62$ \\
\hline Protein & $8.24 \pm 0.05$ & $13.67 \pm 0.35$ & $7.89 \pm 0.22^{\mathrm{b}}$ & $16.28 \pm 0.38^{\mathrm{b}}$ & $15.24 \pm 0.36^{\mathrm{a}}$ \\
\hline Fat & $7.86 \pm 0.29$ & $4.95 \pm 0.18^{\mathrm{a}}$ & $4.39 \pm 0.17^{\mathrm{a}}$ & $4.23 \pm 0.16^{\mathrm{a}}$ & $3.56 \pm 0.15^{\mathrm{b}}$ \\
\hline Carbohydrate & $36.57 \pm 0.51$ & $30.72 \pm 0.45$ & $34.37 \pm 0.49^{\mathrm{b}}$ & $29.65 \pm 0.43$ & $32.27 \pm 0.43$ \\
\hline Ash & $1.04 \pm 0.03$ & $3.42 \pm 0.09$ & $2.15 \pm 0.06$ & $3.59 \pm 0.06$ & $3.64 \pm 0.07$ \\
\hline Energy ( Kcal g ${ }^{-1}$ ) & $249.98 \pm 7.72$ & $222.11 \pm 9.00^{\mathrm{a}}$ & $208.55 \pm 6.88^{\mathrm{b}}$ & $221.79 \pm 7.50^{\mathrm{a}}$ & $222.08 \pm 7.40^{\mathrm{a}}$ \\
\hline
\end{tabular}

Penetration property of DR and NDRs during storage at $4{ }^{\circ} \mathrm{C}$ in a refrigerator

Table 2 revealed the results of the penetration property of DR and NDRs during 30 days of storage at $4^{\circ} \mathrm{C}$. In case of CNDR, penetration value was increased from 0 day of storage $(255.98 \pm 12.48 ; \mathrm{p}<0.05)$ to 10 days of storage $(675.96 \pm 124.96 ; \mathrm{p}<0.05)$. Penetration values then gradually decreased upto $20^{\text {th }}$ $(525.59 \pm 20.59 ; \mathrm{p}>0.05)$ and $30^{\text {th }}$ day of storage $(316.18 \pm 12.48 ; \mathrm{p}>0.05)$. Thus CNDR can be consumed up to 10 days of storage. In case of CLNDR the penetration value was increased from 0 day of storage $(145.96 \pm 10.29 ; p>0.05)$ up to 20 day of storage $(487.49 \pm 20.59 ; \mathrm{p}<0.01)$ and then decreased at 30 day of storage $(389.85 \pm 14.89 ; \mathrm{p}<0.01)$. Thus CLNDR can be consumed up to 20 days of storage. For LNDR penetration values were gradually decreased from 0 day $(565.59 \pm 20.89 ; \mathrm{p}<0.05)$ of storage to 30 days of storage $(201.48 \pm 10.59 ; \mathrm{p}>0.05)$ In case of TNDR penetration values remained constant up to 20 days of storage and then decreased up to 30 day of storage. These results revealed that penetration values of all the five types of rasgulla sample were gradually decreased during the storage period and thus the quality of NDRs made by different coagulants was gradually decreased during storage period. The penetration values of different NDRs were higher than that of control. It can be concluded that penetration properties of NDRs were significantly affected by types of coagulants. The penetration properties of NDR varied significantly with the level of fat and moisture content as well as difference in coagulants. From the present study it can be concluded that among four types of coagulants used for the preparation of NDR from soy milk, tartaric acid is the best coagulant for providing best penetration properties. Nande et al., (2008) showed that texture wise NDRs were rated better than that of DR however, differences were not significant. Fat played a dramatic role in the rheological factors of rasgulla. On the other hand Haque et al., (2003) observed that the chhana produced from cow milk had a soft body and smooth texture, more suitable for rasgulla preparation than soy milk chhana, which had coarse and granular body. Our studies overcome the problem of making NDRs in respect of textural characteristics and tartaric acid coagulant nondairy rasgulla (TNDRs) was most promising among other NDRs in this context.

Table 2 Penetration properties of DR and NDRs using different coagulating agentsduring storage at $4{ }^{\circ} \mathrm{C}$ in a refrigerator

\begin{tabular}{|c|c|c|c|c|c|c|}
\hline Property & $\begin{array}{l}\text { Day of } \\
\text { storage }\end{array}$ & DR & NDRs & & & \\
\hline Penetration at & & & CNDR & LNDR & TNDR & CLNDR \\
\hline $25^{\circ} \mathrm{C}(1 / 10$ th & 0 & $230.29 \pm 12.01$ & $255.98 \pm 12.48^{\mathrm{a}}$ & $565.59 \pm 20.89^{\mathrm{a}}$ & $432.96 \pm 18.59^{\mathrm{a}}$ & $145.96 \pm 10.29^{\mathrm{a}}$ \\
\hline & 20 & $236.48 \pm 35.41$ & $525.59 \pm 20.59$ & $307.78 \pm 18.69^{\mathrm{a}}$ & $433.19 \pm 19.78^{\mathrm{a}}$ & $487.49 \pm 20.59^{b}$ \\
\hline & 30 & $251.26 \pm 39.64$ & $316.18 \pm 12.48$ & $201.48 \pm 10.59$ & $312.78 \pm 12.69^{\mathrm{a}}$ & $389.85 \pm 14.89^{c}$ \\
\hline
\end{tabular}

Results are expressed as mean $\pm \mathrm{SD}(\mathrm{n}=3)$ and significantly different at ${ }^{\mathrm{a}} p<0.05,{ }^{\mathrm{b}} p<0.01$ and ${ }^{\mathrm{c}} \mathrm{p}<0.001$ vs DR (control). DR: Dairy rasgulla; NDRs: non-dairy rasgullas; CNDR: citric acid coagulated non-dairy rasgulla; LNDR: lactic acid coagulated non-dairy rasgulla; TNDR: tartaric acid coagulated non-dairy rasgulla; CLNDR: calcium lactate coagulated non-dairy rasgulla.

Colour properties of DR and NDRs using different coagulating agentsduring storage at $4^{\circ} \mathrm{C}$ in a refrigerator

Change in color in rasgulla samples was an important parameter in assessing the quality of this sweet product. The change of color for all the rasgulla samples was measured over the total storage period from 0 days up to 30 days and was compared. The results were represented in the Table 3 .

A similar trend of $\mathrm{L}^{*}$ values was observed in case of CNDR and DR. $\mathrm{L}^{*}$ values of DR and CNDR were increased from 0 day $(70.50 \pm 0.60 ; \mathrm{p}<0.01$ for DR and $73.60 \pm 0.21 ; \mathrm{p}>0.05$ for $\mathrm{CNDR}$ respectively) to 20 days $(72.96 \pm 0.22 ; \mathrm{p}<0.01$ for $\mathrm{DR}$ and $77.25 \pm 0.22 ; \mathrm{p}<0.01$ for DR and CNDR respectively) were increased and then decreased at $30^{\text {th }}$ day $(71.59 \pm 0.85 ; \mathrm{p}<0.01$ for DR and $72.55 \pm 0.21 ; \mathrm{p}<0.001$ for CNDR respectively). Decrease in $\mathrm{L}^{*}$ values indicated lowering of lightness of rasgulla samples. For LNDR, $\mathrm{L}^{*}$ value initially decreased from 0 day $(73.89 \pm 0.05 ; \mathrm{p}>0.05)$ up to 10 days $(67.52 \pm 0.09 ; \mathrm{p}>0.05)$ of storage. Then it was increased up to 30 days of storage $(70.60 \pm 0.60 ; \mathrm{p}<0.001)$. For TNDR, $\mathrm{L}^{*}$ value gradually decreased from 0 day $(73.89 \pm 0.03 ; \mathrm{p}>0.05)$ up to 30 days $(64.12 \pm 0.02$ $\mathrm{p}<0.001)$ of storage. For CLNDR, $\mathrm{L}^{*}$ value initially decreased and then remained constant for $20(69.53 \pm 0.01 ; \mathrm{p}<0.01)$ and 30 days of storage $(69.52 \pm 0.60$ $\mathrm{p}<0.001)$. Hue-angle values fluctuated in a narrow range of 80-110 during storage. However, chroma had higher values after 20days of storage and then it decreased after 20 days.

Table 3 Colour properties of DR and NDRs using different coagulating agents

\begin{tabular}{|c|c|c|c|c|c|c|}
\hline \multirow[t]{2}{*}{ Sample } & \multirow[t]{2}{*}{ Day } & \multicolumn{5}{|c|}{ Color properties } \\
\hline & & $\mathbf{L}$ & $\mathbf{a}^{*}$ & $\mathbf{b}^{*}$ & c & $\bar{h}$ \\
\hline \multirow[t]{4}{*}{ DR } & 0 & $70.50 \pm 0.60$ & $-1.80 \pm 0.05$ & $9.89 \pm 0.30$ & $10.23 \pm 0.40$ & $100.4 \pm 8.03$ \\
\hline & 10 & $71.25 \pm 0.69$ & $-1.56 \pm 0.01$ & $11.54 \pm 0.96$ & $11.14 \pm 0.33$ & $96.58 \pm 0.59$ \\
\hline & 20 & $72.96 \pm 0.39$ & $-1.73 \pm 0.02$ & $10.57 \pm 0.39$ & $10.37 \pm 0.26$ & $101.26 \pm 0.93$ \\
\hline & 30 & $71.59 \pm 0.85$ & $-0.99 \pm 0.03$ & $9.85 \pm 0.24$ & $9.86 \pm 0.29$ & $103.29 \pm 1.06$ \\
\hline \multicolumn{7}{|l|}{ NDRs } \\
\hline \multirow[t]{4}{*}{ CNDR } & 0 & $73.60 \pm 0.21$ & $-0.91 \pm 0.04$ & $10.93 \pm 0.12^{\mathrm{c}}$ & $11.11 \pm 0.12^{\mathrm{c}}$ & $89.10 \pm 4.23$ \\
\hline & 10 & $74.05 \pm 0.20$ & $-0.82 \pm 0.03^{\mathrm{a}}$ & $12.10 \pm 0.14$ & $12.10 \pm 0.14$ & $80.25 \pm 0.75^{\mathrm{b}}$ \\
\hline & 20 & $77.25 \pm 0.22^{\mathrm{b}}$ & $-1.00 \pm 0.01$ & $11.99 \pm 0.03$ & $11.92 \pm 0.03$ & $87.43 \pm 0.59$ \\
\hline & 30 & $72.55 \pm 0.21^{\mathrm{c}}$ & $-0.72 \pm 0.05^{\mathrm{b}}$ & $9.83 \pm 0.07^{\mathrm{b}}$ & $9.83 \pm 0.07^{\mathrm{b}}$ & $87.36 \pm 2.80$ \\
\hline LNDR & 0 & $73.89 \pm 0.05$ & $-0.76 \pm 0.05$ & $10.84 \pm 0.23^{\mathrm{c}}$ & $10.86 \pm 0.23^{c}$ & $93.76 \pm 3.12$ \\
\hline
\end{tabular}




\begin{tabular}{|c|c|c|c|c|c|c|}
\hline & 10 & $67.52 \pm 0.09$ & $-1.20 \pm 0.01^{\mathrm{a}}$ & $9.59 \pm 0.08$ & $9.53 \pm 0.08$ & $113.53 \pm 0.75^{b}$ \\
\hline & 20 & $69.51 \pm 0.01^{\mathrm{b}}$ & $-1.05 \pm 0.00$ & $13.23 \pm 0.09$ & $13.23 \pm 0.09$ & $83.96 \pm 6.80$ \\
\hline & 30 & $70.60 \pm 0.60^{c}$ & $-0.63 \pm 0.05^{b}$ & $11.17 \pm 0.06^{\mathrm{b}}$ & $11.11 \pm 0.06^{\mathrm{b}}$ & $90.23 \pm 5.23$ \\
\hline \multirow[t]{4}{*}{ TNDR } & 0 & $73.89 \pm 0.03$ & $+0.76 \pm 0.06$ & $13.97 \pm 0.10^{\mathrm{c}}$ & $13.92 \pm 0.10^{\mathrm{c}}$ & $87.16 \pm 5.31$ \\
\hline & 10 & $67.23 \pm 0.06$ & $1.01 \pm 0.07^{\mathrm{a}}$ & $15.26 \pm 0.09$ & $15.23 \pm 0.09$ & $84.29 \pm 4.34^{b}$ \\
\hline & 20 & $69.21 \pm 0.04^{\mathrm{b}}$ & $0.63 \pm 0.05$ & $13.89 \pm 0.14$ & $13.89 \pm 0.14$ & $85.76 \pm 4.61$ \\
\hline & 30 & $64.12 \pm 0.02^{\mathrm{c}}$ & $0.83 \pm 0.07^{\mathrm{b}}$ & $15.33 \pm 0.03^{\mathrm{b}}$ & $15.33 \pm 0.03^{\mathrm{b}}$ & $82.33 \pm 5.30$ \\
\hline \multirow[t]{4}{*}{ CLNDR } & 0 & $73.89 \pm 0.05$ & $-0.19 \pm 0.00$ & $11.09 \pm 0.23^{\mathrm{c}}$ & $11.06 \pm 0.23^{\mathrm{c}}$ & $90.53 \pm 3.12$ \\
\hline & 10 & $67.52 \pm 0.09$ & $-1.28 \pm 0.03^{\mathrm{a}}$ & $9.69 \pm 0.08$ & $9.63 \pm 0.08$ & $113.43 \pm 0.75^{b}$ \\
\hline & 20 & $69.53 \pm 0.01^{\mathrm{b}}$ & $-1.04 \pm 0.01$ & $13.36 \pm 0.09$ & $13.36 \pm 0.09$ & $83.33 \pm 5.89$ \\
\hline & 30 & $69.52 \pm 0.60^{\mathrm{c}}$ & $-0.53 \pm 0.01^{\mathrm{b}}$ & $11.23 \pm 0.06^{\mathrm{b}}$ & $11.23 \pm 0.06^{\mathrm{b}}$ & $90.19 \pm 5.23$ \\
\hline
\end{tabular}

Results are expressed as mean $\pm \mathrm{SD}(\mathrm{n}=3)$ and significantly different at ${ }^{\mathrm{a}} p<0.05,{ }^{\mathrm{b}} p<0.01$ and ${ }^{\mathrm{c}} \mathrm{p}<0.001$ vs DR (control). $\mathrm{L}^{*}$ value represents lightness and darkness with a range from black $(0)$ to white $(100)$, a*value represents the green-red spectrum with a range from green $(-100)$ to red $(+100)$, while $b^{*}$ value represents blue-yellow spectrum with a range from blue $(-100)$ to yellow $(+100)$. c value represents chroma and $\mathrm{h}$ value represents hue angle. DR: Dairy rasgulla, NDR: Non-dairy rasgulla, NDR: CNDR: citric acid coagulated non-dairy rasgulla; LNDR: lactic acid coagulated non-dairy rasgulla; TNDR: tartaric acid coagulated non-dairy rasgulla;

CLNDR: $\quad$ calcium lactate

Sensory evaluation of DR and NDRs during storage at $4{ }^{\circ} \mathrm{C}$ in a refrigerator

The sensory evaluation of DR and NDRs produced using various coagulants and stored at $4^{0} \mathrm{C}$ for 30 days was shown in Table 4. The results revealed that genera acceptability of DR and NDRs was gradually decreased during storage as exemplified by color, aroma and texture of rasgulla samples.

The mean scores of DR and NDRs for color gradually decreased on storage. LNDR showed a significantly lower score $(5.59 \pm 0.15 ; \mathrm{p}<0.05)$ for color than DR $(6.29 \pm 0.85 ; \mathrm{p}>0.05)$ other NDRs prepared using CNDR $(7.08 \pm 0.69 ; \mathrm{p}>0.05)$ TNDR $(7.06 \pm 0.19 ; \mathrm{p}<0.05)$ and CLNDR $(6.75 \pm 0.18 ; \mathrm{p}<0.001)$ on $30^{\text {th }}$ day of storage.

The mean aroma score of DR and NDRs produced using different coagulants was also decreased during storage. Results showed that this decrease was more significant in case of DR $(6.33 \pm 0.59 ; \mathrm{p}>0.05), \mathrm{CNDR}(6.43 \pm 0.69 ; \mathrm{p}>0.05)$ and LNDR $(6.40 \pm 0.18 ; \mathrm{p}>0.05)$ at $30^{\text {th }}$ day of storage.

A decreasing trend of mean texture score was observed for all the types of NDRs including DR during the storage period. A significant lower texture score was observed for LNDR at $30^{\text {th }}$ day of storage $(6.28 \pm 0.18 ; \mathrm{p}>0.05)$.

$$
\text { coagulated non-dairy rasgulla }
$$

In general over all acceptability for NDR and DR were gradually decreased from 0 day of storage and it was lowest for 30 days of storage. Over all acceptability scores of NDR prepared from LNDR was lower $(6.11 \pm 0.17 ; \mathrm{p}>0.05)$ than that of other NDRs and DR for the storage period. Relatively lower overall acceptability scores for LNDR were due to lower scores for other sensory attributes. Overall acceptability scores for TNDR $(7.63 \pm 0.22 ; \mathrm{p}<0.01)$ and CLNDR $(7.65 \pm 0.22$ $\mathrm{p}<0.001)$ were significantly higher among all treatments throughout the period of storage. Thus, on the basis of analysis of different physicochemical and sensory parameters, tartaric acid proved to be optimum in the preparation of NDR.

The result revealed that overall acceptability of LNDR was lower than that of DR. On the other hand it was observed that CNDR, TNDR and CLNDR had higher overall acceptability than DR. These findings were similar with the observations of Nande et al., (2008), Katara and Bhargava, (1990) who showed that slightly lower score in overall acceptability was obtained when the attribute of appearance of NDRs was compared with that of DR.

\begin{tabular}{llllll} 
Table 4 Sensory properties of DR and NDRs using different coagulating agents during storage at $4^{\circ}$ C in a refrigerator \\
\hline Sample & Day & Colour & Texture & Aroma & $\begin{array}{l}\text { Overall } \\
\text { acceptability }\end{array}$ \\
\hline DR & 0 & & & $8.83 \pm 0.26$ & $8.95 \pm 0.28$ \\
& 10 & $7.12 \pm 0.29$ & $8.95 \pm 0.29$ & $6.52 \pm 0.67$ & $7.42 \pm 0.98$ \\
& 20 & $6.59 \pm 0.39$ & $7.14 \pm 0.58$ & $6.41 \pm 0.48$ & $6.69 \pm 0.69$ \\
\hline CNDR & 30 & $6.29 \pm 0.85$ & $7.26 \pm 0.48$ & $6.33 \pm 0.59$ & $6.28 \pm 0.47$ \\
& 0 & $7.35 \pm 0.29^{\mathrm{a}}$ & $8.54 \pm 0.35^{\mathrm{b}}$ & $6.93 \pm 0.20^{\mathrm{c}}$ & $7.69 \pm 0.33^{\mathrm{c}}$ \\
& 10 & $7.29 \pm 0.59^{\mathrm{b}}$ & $8.47 \pm 0.59^{\mathrm{a}}$ & $6.84 \pm 0.69$ & $7.68 \pm 0.85^{\mathrm{a}}$ \\
LNDR & 20 & $7.11 \pm 0.89^{\mathrm{a}}$ & $7.89 \pm 0.47$ & $6.57 \pm 0.57$ & $7.53 \pm 0.96^{\mathrm{a}}$ \\
& 30 & $7.08 \pm 0.69^{\mathrm{a}}$ & $7.87 \pm 0.69$ & $6.43 \pm 0.69$ & $7.40 \pm 0.59$ \\
& 0 & $6.25 \pm 0.23^{\mathrm{b}}$ & $7.53 \pm 0.28^{\mathrm{b}}$ & $6.98 \pm 0.21^{\mathrm{c}}$ & $6.59 \pm 0.28^{\mathrm{c}}$ \\
TNDR & 10 & $6.11 \pm 0.16^{\mathrm{b}}$ & $7.40 \pm 0.20^{\mathrm{a}}$ & $6.77 \pm 0.17$ & $6.43 \pm 0.16$ \\
& 20 & $6.02 \pm 0.15^{\mathrm{a}}$ & $7.33 \pm 0.18^{\mathrm{a}}$ & $6.47 \pm 0.16^{\mathrm{a}}$ & $6.20 \pm 0.46$ \\
& 30 & $5.59 \pm 0.15^{\mathrm{a}}$ & $6.28 \pm 0.18$ & $6.40 \pm 0.18$ & $6.11 \pm 0.17$ \\
& 0 & $8.12 \pm 0.28^{\mathrm{a}}$ & $8.16 \pm 0.30^{\mathrm{b}}$ & $7.68 \pm 0.32^{\mathrm{c}}$ & $8.20 \pm 0.46^{\mathrm{c}}$ \\
CLNDR & 10 & $8.02 \pm 0.30^{\mathrm{b}}$ & $8.01 \pm 0.29$ & $7.63 \pm 0.27^{\mathrm{a}}$ & $8.11 \pm 0.31^{\mathrm{b}}$
\end{tabular}

Results are expressed as mean $\pm \mathrm{SD}(\mathrm{n}=3)$ and significantly different at ${ }^{\mathrm{a}} p<0.05,{ }^{\mathrm{b}} p<0.01$ and ${ }^{\mathrm{c}} \mathrm{p}<0.001$ vs DR (control). DR: Dairy rasgulla; NDRs: non-dairy rasgullas; CNDR: citric acid coagulated non-dairy rasgulla; LNDR: lactic acid coagulated non-dairy rasgulla; TNDR: tartaric acid coagulated non-dairy rasgulla; CLNDR: calcium lactate coagulated non-dairy rasgulla.

In vitro multienzyme protein digestibility of DR and NDRson 0 day at $4{ }^{\circ} \mathrm{C}$ in a refrigerator

Fig 2 showed the result of in vitro multienzyme protein digestibility of DR and NDRs produced using various coagulants. The result revealed that there was significant difference in the digestibility of TNDR $(121.77 \pm 1.55 ; \mathrm{p}<0.01)$ when compared to CNDR $(88.12 \pm 1.05 ; \mathrm{p}<0.05)$, LNDR $(83.76 \pm 1.06 ; \mathrm{p}<0.05)$ and CLNDR $(87.38 \pm 1.04 ; \mathrm{p}<0.05)$. In vitro multienzyme protein digestibility of TNDR $(121.77 \pm 1.55 ; \mathrm{p}<0.01)$ was significantly higher than that of DR (100.25 \pm 2.54$)$. LNDR, CNDR and CLNDR had lower protein digestibility values than control DR. LNDR had the lowest $(83.76 \pm 1.06$; $\mathrm{p}<0)$ value. The differences in the in vitro protein digestibility of NDRs may be due to differences in the coagulating ability of each of the coagulant with regard to the different type of proteins in the presence of the various protease inhibitors (Hwang et al., 1978).
Differences in the digestibility of rasgulla may be due to interaction of Tannin, trypsin and chymotrypsin inhibitors with the protein. 


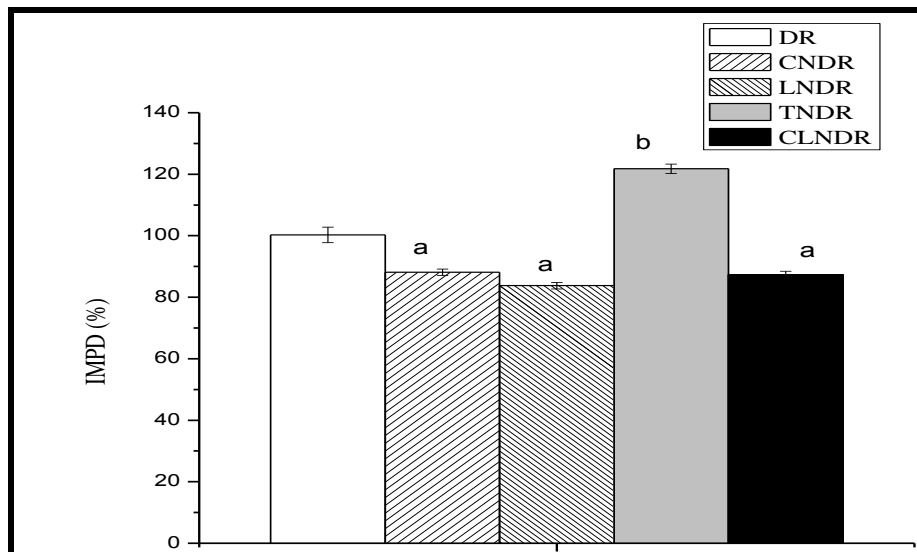

DR (Control) AND NON-DAIRY RASGULLA(NDR)

Fig 2 In Vitro Mutienzyme Protein Digestibility (IMPD) of DR and NDRs using different coagulating agents

DR: dairy rasgulla, NDR: Non-dairy rasgulla; DR: dairy rasgulla; CNDR: citric acid coagulated non-dairy rasgulla; LNDR: lactic acid coagulated non-dairy rasgulla; TNDR: tartaric acid coagulated non-dairy rasgulla; CLNDR: calcium lactate coagulated non-dairy rasgulla

\section{CONCLUSION}

Suitability of different coagulants (citric acid, tartaric acid, lactic acid and calcium lactate) for the manufacture of rasgulla was evaluated on the basis of proximate composition, hardness, color values and sensorial attributesand were compared with the respective values of most preferred of dairy rasgulla procured from market. Rasgulla manufactured using lactic acid, lack sensorial attributes, hardness and color values and accordingly was found unsuitable for better quality product. Tartaric acid coagulated NDR had significantly higher protein, ash, total solids, energy content and protein digestibility content, as well as the best sensory quality evaluated. Thus tartaric acid gave higher overall acceptability of rasgulla and was found the most suitable coagulant for manufacturing non-dairy rasgulla.

\section{CONFLICT OF INTEREST}

The authors are unanimous in publishing this paper. There is also no body to contradict this manuscript.

\section{REFERENCES}

Ahmed A.R., Vyas, S.H., Upadhyay, K.G., \&Thakar, P.N. (1981). Study on manufacture of chhana from buffalo milk. Gujarat Agricultural University research journal, 7, 32-38.

Aneja, R.P., Mathur B.N., Chandan, R.C., \& Banerjee, A.K. (2002). Technology of Indian Milk Products. Dairy India Publication, Delhi, India, ISBN-10: 81901603-0-3

Association of Official Agricultural Chemist, AOAC. (2005). Official Methods of Analysis of AOAC International(18th ed.). Maryland: AOAC International

Bhattacharya, D.C., \& Raj, D. (1980). Studies on production of rasogolla. I. Traditional method, Indian Journal of Dairy Science, 33, 237-243.

Bandyopadhyay, M., Chakraborty, R. \& Raychaudhuri, U. (2005).The effect of coagulants on the texture of chhana (an acid and heat coagulated product made from milk). International Journal of Food Science \& Technology, 40(8), 799. 810. http://doi.org/10.1111/j.13652621.2005.00979.x

Bandyopadhyay, M., Chakraborty, R. \&Raychaudhuri, U. (2008).Effect of carrot on quality improvement of sweet syrup cheese ball (rasgulla).International Journal of Dairy Technology, 61(3), 290-299. http://doi.org/10.1111/j.13652621.2005.00979.x

Barrett, J. R. (2006). The Science of Soy: What Do We Really Know? Environmental Health Perspectives, 114(6), A352-A358.

Chavan, R.S., Prajapati, P.S., Chavan, S.R. \&Khedkar, C.D. (2009). Study of manufacture and shelf-life of Indian dietetic and diabetic rosogolla. International Journal of Dairy Science, 4, 129-141.http://doi.org/10.3923/ijds.2009.129.141

Garg, P., Raghav, P.K., Sharma, R.K., Jasuja, N. D. Sharma, R. \&Agarwal, N. (2004). Development of Mucilaginous Spongy Dessert-A Herbal Rassogolla Prepared from Cow Milk.International Journal of Scientific and Research Publications, 4(2), 2250-3153.

Haque , A., Alam, M.J., Hasanuzzaman , M., Islam, M.N. \& Azad, M.A.K. (2003). Comparison of Rasogolla Made from Fresh Cow Milk, Fresh Buffalo Milk and Mixture of Cow and Buffalo Milk. Pakistan Journal of Nutrition, 2(5), 296-299.
Hsu, W.W., Vavak, D.L., Satteriee, L.D. \& Miller, G.A. (1977).A multienzyme technique for estimating protein digestibility.Journal of Food Science,42(5), 1269-1273.http://doi.org/ 10.1111/j.1365-2621.1977.tb14476.x

Hwang, D.L., Yang, W.K., Foard, D.E., \& Lin, K.T.D. (1978). Rapid Release of Protease Inhibitors from Soybeans: Immunochemical Quantitation and Parallels with Lectins. Plant Physiology, 61(1), 30-34.

Jooyandeh, H. (2011).Soy Products as Healthy and Functional Foods.MiddleEast Journal of Scientific Research, 7 (1), 71-80.

Katara, R.V., \& Bhargava, V.N. (1990). Production of rasogolla from cow milk containing different levels of soymilk. Asian Journal of Dairy Research, 9(4), 175-180.

Kolanoyski, J. (1977). On the mechanisms of fasting natriuresis and of carbohyllate induced sodium retention. Diabète\&metabolisme,3(2),131-143.

Morales F. J., \& Van Boeckel, M. A. J. S. (1999). A study on advanced Maillard reaction in heated casein/sugar solutions: colour formation. International Dairy Journal, 8, 907-915.

Merrill, A.L., \& Watt, B.K. (1973). Energy value of foods: basis and derivation.Agriculture handbook 74. Washington, DC: US Department of Agriculture, Agricultural Research Service.

Nande, P., Tapadia, P., Jain, K.,FrenalL., \&Sabiha, V.A. (2008). A Study on Soymilk as a Substitute for Animal Milk. Journal of dairying, foods \& home sciences, 27 (1), $1-10$.

Rao, S., Rao, M.M., Ranganadham, M. \&Rao, B.V.R. (1989).Studies on preparation of chhana from buffalo milk and its suitability for rasogollamanufacture.Indian Journal of Dairy Science, 42, 810-816.

Sahu, J.K., \& Das, H. (2009).A continuous heat-acid coagulation unit for continuous production of chhana.Assam University Journal of Science \& Technology: Physical Sciences and Technology,4(II), 40-45.

Sanli, T., Gursel, A., Anli, E.S., Acar E., \&Benli, M. (2013).The effect of using an exopolysaccharide-producing culture on the physicochemical properties of low-fat and reduced-fat Kasar cheeses. International Journal of Dairy Technology, 66 (4), 535-542.

Sengupta, S., Bhowal, J., \& Bhattacharyya, D.K. (2013). Development of new kinds of soy yogurt containing functional lipids as superior quality food.Annals of Biological Research,4,144-151.

Sengupta, S., Goswami, R., Basu, S., \& Bhowal, J. (2016). Hypolipidemic effects of soy yogurt fortified with antioxidant rich vegetable oil on albino mice fed high cholesterol diet. Materials Today: Proceeding, 3 (2016), 3222-3237. http://dx.doi.org/10.1016/j.matpr.2016.10.004

Tarafdar, S. U., Pramanik, M.A.H., Basak, B., Rahman, M.S., \& Biswas S.K. (2002). A Comparative Study on the Quality of Rasogolla Made in Laboratory and Collected from Local Markets of Mymensingh, Bangladesh. Pakistan Journal of Nutrition, 1(3), 156-160.

Wang, H.J., \& Murphy, P.A. (1994).Isoflavone content in commercial soybean foods.Journal of Agricultural and Food Chemistry, 42, 1666-1673.

Yadav, D., Vij, S., Hati, S., Singh, B.P., Dhanday, M., Dahiya,M., \&Vandna (2012). Evaluation of total antioxidant activity of soy yoghurt, Indian Journal of Dairy Science, 65(3), 220- 224.http://dx.doi.org/10.5146/ijds.v65i3.25874

Yakubu, N., Oboh, G., \&Olalekan, A. A. (2013).Antioxidant and Hepatoprotective Properties of Tofu (Curdle Soymilk) against AcetaminophenInduced Liver Damage in Rats.Biotechnology Research International, 2013, 230142-230148. http://doi.org/10.1155/2013/230142 